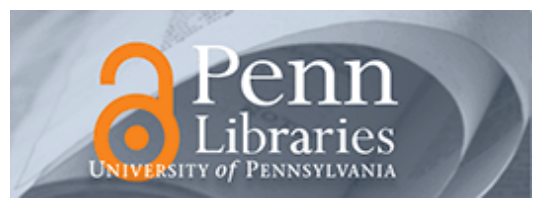

University of Pennsylvania

ScholarlyCommons

Operations, Information and Decisions Papers

Wharton Faculty Research

6-2006

\title{
Achieving Breakthrough Service Delivery Through Dynamic Asset Deployment Strategies
}

Morris. A. Cohen

University of Pennsylvania

Narendra Agrawal

Vipul Agrawal

Follow this and additional works at: https://repository.upenn.edu/oid_papers

Part of the Organization Development Commons, and the Other Education Commons

\section{Recommended Citation}

Cohen, M. A., Agrawal, N., \& Agrawal, V. (2006). Achieving Breakthrough Service Delivery Through Dynamic Asset Deployment Strategies. Interfaces, 36 (3), 259-271. http://dx.doi.org/10.1287/inte.1060.0212

This paper is posted at ScholarlyCommons. https://repository.upenn.edu/oid_papers/217

For more information, please contact repository@pobox.upenn.edu. 


\title{
Achieving Breakthrough Service Delivery Through Dynamic Asset Deployment Strategies
}

\author{
Abstract \\ Many firms have shifted their focus from their products to their customers and the value derived from \\ owning and using the products. They see after-sales service as an important source of revenue and profit, \\ customer acquisition and retention, and competitive differentiation. However, they also find it challenging \\ to manage their service-supply chain. Service organizations must position and manage service-supply- \\ chain resources optimally to support the delivery of after-sales service. They must also develop \\ capabilities to respond rapidly to the demand for service in a cost-effective manner. To succeed in \\ implementing a service-centric strategy, firms must determine what items in their products' service bill-of- \\ material hierarchy should be deployed throughout their geographical hierarchy of service support \\ locations. They must make these complex and interrelated decisions in anticipation of service demand, \\ which is uncertain. Firms must also be flexible and should understand the mechanisms in a service- \\ supply chain needed to fulfill customers' demands for service and the resulting demands for support \\ assets and capacities. Dynamic asset deployment (DAD), a collection of management policies that \\ promote this flexibility, can be used to develop the capabilities needed to effectively and profitably deliver \\ services. These policies require a real-options-based optimization approach to decision making.
}

\section{Keywords}

inventory, production, multi-item, multiechelon, industries, telecommunications

\author{
Disciplines \\ Organization Development | Other Education
}




\title{
Achieving Breakthrough Service Delivery Through Dynamic Asset Deployment Strategies
}

\author{
Morris A. Cohen \\ Matsushita Professor of Manufacturing and Logistics \\ The Wharton School \\ University of Pennsylvania \\ Chairman/Founder MCA Solutions Inc. \\ Morris.cohen@mcasolutions.com \\ Narendra Agrawal \\ Associate Professor \\ Leavey School of Business \\ Santa Clara University \\ nagrawal@scu.edu \\ Vipul Agrawal \\ Executive Vice President, Products/Cofounder MCA Solutions Inc. \\ Vipul.Agrawal@mcasolutions.com
}

March 14, 2004 


\section{INTRODUCTION}

The last decade has witnessed a substantial shift in emphasis on the part of many firms from a focus on the products they produce to a concentration on their customers and the value that their customers derive from ownership and use of these products. This "customer-centric" perspective is correlated with the blurring of the line between products and services. Consider the examples of companies like Hewlett Packard and IBM. Historically, they have competed by positioning themselves as manufacturers of cutting edge, high-technology products. However, recent years have witnessed a shift in their competitive strategy towards providing technology solutions, of which, services is a very significant component. In fact, today, most firms would describe their output as a bundle of goods and services and are seeing significant growth in the proportion of their revenue derived from services. For example, in 2001, maintenance servicing was responsible for over $\$ 5$ billion of IBM's revenues. A recent survey by AMR, (Bijesse et al [2002]), puts this percentage at 24\% with many traditional manufacturing firms at over $50 \%$ and climbing, as reported in a recent Wharton-Stanford conference on the after-sales service industry, (see http://opim.wharton.upenn.edu/fd/forum/). Not surprisingly, therefore, companies are beginning to direct their focus on their service supply chains, which we define as the network of resources that includes the appropriate material (service parts), people (customer engineers, call center staff, report depot staff, warehouse and transportation staff) and infrastructure, (for material movement and storage, repair, transportation, information systems, and communication).

This shift towards a service-centric strategy represents an important aspect of firms' efforts towards enhancing overall revenue and profit, customer acquisition and retention, and competitive differentiation, as explained below:

- Revenue and profit enhancement

o It is easier to increase the sales of parts and service related products (repair, upgrade, support, etc.) to existing customers than to increase sales of the primary product. This trend has been reinforced in industries facing an economic slowdown, where owner/operators are looking to prolong the useable life and increase the availability of their equipment, thereby decreasing their overall cost of ownership.

o Provision of such after-sales service to support the installed base of existing products and customers provides a low risk revenue stream over a long-term period of ownership (e.g., up to 25 years in aerospace).

o Profit margins for services are much higher than the margins associated with the sale of products. The margins for existing products, moreover, are decreasing as many products become increasingly commoditized and/or duplicated by competitors. For example, the AMR study cited above observed that while service represents $24 \%$ of revenue, it generated $45 \%$ of the profit in their sample. Similar statistics have been reported in a number of industry specific studies (see Dennis and Kambil (2003) and Wise and Baumgartner (1999)).

- Customer acquisition and retention

o It is increasingly difficult and expensive for firms to find new customers and to increase revenues based on the sale of their finished products.

o The infrastructure and knowledge base associated with the customers' installed base cannot be easily replicated and hence provides a sustainable source of competitive advantage.

Draft - Do not distribute without permission Copyright 2004 
- Competitive differentiation

o Escalating customer expectations for rapid, flawless service support have increased the opportunity for firms to profit from appropriately priced differentiated service products targeted to meet the needs of particular market segments. Exploitation of the willingness to pay for service across these segments opens up the opportunity to increase profit through optimized pricing and service product strategies.

o Execution level systems (ERP, CRM) have enhanced the visibility of transactions associated with customer service throughout a firm's extended value network. This visibility has opened up new opportunities for collaboration and revenue generation with upstream suppliers and downstream customers.

o New technologies for automated remote diagnosis, and even repair, have increased the possibilities for increased efficiency that can benefit both the product provider and the customer.

o The designer and producer of a product has access to superior knowledge that supports service support, e.g., sources of supply, service Bill of Material, failure modes and rates, etc.

As the distinction between products and services has diminished, the attribution of revenue to one aspect or the other of the firm's output has become more difficult and perhaps less relevant. On the other hand, the mechanisms required to design, produce and deliver service products in a cost-effective and competitive manner are quite different than those used to manufacture goods and to procure direct materials. Indeed, the management of this service supply chain remains a challenge. It is, therefore, not surprising that significant assets must be dedicated towards service delivery. At Boeing, for example, spare parts supporting its aircraft around the world alone represent over $\$ 7$ billion of very slow moving investment (Liang 2002).

In this paper we will focus on the emerging discipline of service supply chain management with specific emphasis on the services associated with after-sales customer support. We will, in particular, describe the service-centric strategies that many firms are adopting in this space as they respond to the realities of current economic conditions. Our emphasis will be on the following two critical questions

a) Service Asset Management: How should service supply chain resources be positioned and controlled to support delivery of after-sales service?

b) Service Demand Fulfillment: What is the most cost effective way to deliver such service?

As we shall see, it is especially difficult to answer these management questions for after-sales service supply chains as a consequence of their high level of complexity and risk. A key conclusion of our analysis will be that traditional modes of thinking, which are inspired by manufacturing and finished product distribution thinking (e.g., ERP and DRP), and which attempt to match service supply to demand by assigning enabling resources to specific service products in a static and separable fashion, are inefficient and ineffective. The requirement for competitive success in delivering a service-centric strategy is flexibility. Such flexibility must be based on a deep understanding of the mechanisms that come into play in a service supply chain to fulfill customer demands for service. We shall introduce a collection of management policies that promote this flexibility and refer to it as Dynamic Asset Deployment (DAD). We shall propose a framework that can be used to design such policies and describe the most significant capabilities that a firm must develop to compete profitably through them to effectively deliver services. Our research and experience in implementing such strategies at a number of companies in diverse industries leaves no doubt that firms that do not adopt such dynamic strategies are destined to mediocrity when it comes to competing on the basis of customer service. 
The key to understanding dynamic asset management and using it to support successful customer-centric strategies is the fact that after-sales service products purchased by customers are equivalent to "entitlements" for response to a support need within a specified time limit, at a given level of reliability and for a given price. Such service products cannot be produced in advance of their demand and thus they cannot be stored on the shelf. Rather they are produced at the time of consumption, which is typically triggered by a contingency, or a random "service event," such as the failure of an installed product in the field. Such events are very difficult to predict. Fulfillment of service product demands, however, is enabled by physical assets such as spare parts inventory, repair depot capacity and field engineer contact hours. These assets must be deployed in advance of the occurrence of a service event if the response time entitlement standard is to be met, (e.g., responding within minutes or hours). These assets are utilized or consumed as the service response is produced to meet the specific requirements of a given service event.

In this paper we propose that firms adopt the principles of dynamic asset deployment, to design their service products and to manage the deployment and utilization of enabling resources in the processes used to fulfill service product demands. Specifically we propose the following recommendations for developing a DAD enabled customer-centric service strategy:

1. Recognize that a service product represents a commitment to customers that the product they have purchased will provide a guaranteed level of value creation. Accordingly, design and deliver such service products based on metrics directly related to customer satisfaction (e.g., equipment uptime) and link service product prices and revenues to achieved performance.

2. Optimize service asset management decisions that determine the capacity, location and capabilities of the resources that are consumed and/or utilized in the course of fulfilling service demands. Optimization requires that these decisions be made in a manner that explicitly accounts for the tradeoffs in cost and service quality that are driven by the dynamics and uncertainties associated with service demand and service resource supply processes. We propose, in particular, that firms adopt a risk management perspective supported by the use of appropriate solution algorithms. Such algorithms must consider the complex interactions among decisions throughout the service supply chain, as well as the sources and mechanisms that introduce risk.

3. Use integrated decision support tools to support efficient service product demand fulfillment. In particular, maintain customer service quality entitlements by linking asset management decisions and process execution systems to a common database driven by real time visibility of the underlying service related transactions. The fulfillment process must also take into account the potentially competing priorities for resources driven by service product commitments to customers.

4. Include feedback derived from actual after sales product field experience to product design and improvement processes. The overall goal is to integrate service factors into the overall product architecture ("Design for Serviceability"), and to respond to performance issues through part engineering change.

5. Design the service supply chain network to be consistent with the firm's service strategy. This includes consideration of outsourcing of the infrastructure needed to deliver service through use of $3^{\text {rd }}$ and $4^{\text {th }}$ party service and logistics providers. In general, determine the appropriate mix of providers that can be integrated to support flexible and efficient response mechanisms.

Making good on these recommendations will require companies to adopt a wholly new paradigm for service supply chain management. The approach proposed here is analogous to treating service delivery as a real option, i.e., resource investments are required to "purchase" the option to deliver service and subsequently random contingencies occur that determine how the option will be "exercised" as the service requirement is fulfilled. 


\section{ILLUSTRATIVE CASE STUDIES}

In order to illustrate the requirements for DAD policy implementation, consider the case of Cisco Systems, a leading high technology manufacturer of computer, data storage, communication and related equipment. Their products are used in a wide range of industries to support e-commerce and information system coordination. Cisco's service supply chain is characterized by the following attributes:

- 3-5 echelons consisting of nearly 750 stocking locations (including a central depot, regional warehouses, local warehouses and forward locations positioned at or near major customer sites).

- Multiple customer classes defined in terms of service contract performance targets (i.e., high priority with 2-4 hour response time guarantee, 8-12 hour response time and next business day response time). There are millions of such contracts.

- Hundreds of supported products that are mission critical to customers (e.g., net servers, communication systems).

- Over 100,000 part numbers supported throughout the service supply chain.

- Strategic parts inventory deployment decisions including the setting of Target Stocking Levels (TSL's) for every part-location combination (more than 75 million in this case!).

- A highly dynamic environment characterized by tens of thousands of service contract transactions (new or changes) and thousands of service event fulfillment transactions (material flows) per day.

The challenge facing Cisco's service support function is to manage the resources and business processes under its control in a manner that effectively supports the firm's overall service-centric strategy. This strategy is based on the sale of multiple classes of support contracts to global customers that specify meeting specific response time requirements for deployed customer owned equipment with a very high level of reliability. Such contracts also specify the locations, service bills of material and the assigned forward response site for every piece of equipment to be supported. Many of their larger customers maintain many different contracts covering specific sets of products and support locations to capture heterogeneous service needs. The goal of these contracts is to support a high level of customer product uptime, i.e., product availability. At any given stocking location, Cisco also has a population of customers that are not covered by service contracts. Demand for service parts and support from these non-contract customers competes for resources with the demand associated with contract customers. Cisco's service strategy goal is to deliver these diverse service products to their customers with a near perfect level of availability. They also want to do so while meeting targets for reducing their resource investments and costs. Specific targets for fill rate and resource utilization (measured by the ratio of inventory investment to service revenue) have been specified.

Similar complexity of the service supply chain is typical in many other industries that utilize capital-intensive equipment whose downtime is extremely expensive. For example, San Jose, California based KLA-Tencor, the world leader in yield management and process control solutions for the semiconductor manufacturing industry, offers a broad portfolio of products installed in more than 400 customer fabrication plants (fabs) around the world. In order to maintain competitive yields and capacity utilization at these fabs, such expensive equipment must operate at very high levels of availability. Accordingly, KLA-Tencor operates in a very complex and exacting service delivery environment characterized by massive cyclic variations in capacity utilization, high levels of market volatility and rapid technological development. 
Yet another example is a company like Boeing, which sells and supports, among other products, aircraft to airlines and to defense services around the world. "Uptime" of these planes and the availability of various onboard systems (such as radars and weapons systems), is understandably mission critical. However, as compared to Cisco or KLATencor, the customer's product (plane's) location is constantly shifting, and the demand for service is predicated on factors that are beyond the control of management and are very difficult to predict, (e.g., military campaigns, seasonal flying promotions, etc.). 


\section{SERVICE ASSET MANAGEMENT}

As we have noted, a goal of a firm's service supply chain is to maximize the benefit their customers derive from ownership and use of the products they have purchased. In doing so, the firm seeks to maximize the profit that it derives, both directly and indirectly, through provision of a portfolio of diverse service products to a heterogeneous group of customers with a geographically distributed installed equipment base which requires support. The unprecedented levels of service demanded by today's service-centric competitive environment require that firms find fundamentally different ways to think about service delivery. In particular, the static asset deployment principles currently used by most firms will need to be replaced by a new set of approaches which we referred to as $\mathrm{DAD}$. These policies must be designed in a manner that takes advantage of the unique inter-relationships between resources, decisions and information that characterize the service supply chain environment. This requires companies to develop a detailed understanding of 3 key issues:

- Key tradeoffs associated with service delivery.

- Strategic options for deploying various service delivery assets.

- Effect of asset deployment decisions on service delivery tradeoffs.

Each issue is discussed in detail in the following paragraphs.

\section{Tradeoffs for Service Delivery}

The principal tradeoff facing service supply chain managers is between revenue, cost and service performance. Let us consider each of these metrics in turn before discussing tradeoffs among them and their implications for asset management.

Service revenue is derived from the sale of service products designed to support customers' requirements for uninterrupted use of their products. Such revenue can be captured through performance based service contracts and/or the direct sale of time (customer engineer, repair depot, etc.) and material (replacement parts). Many firms also address their customers' expectation for service through provision of product warranties that act as a pre-paid service contract operating for a fixed period of time at the beginning of the ownership cycle. As a consequence, the revenue model for service should include the initial sale price of the product, the terms of the warranty, the design and price of the service support contracts sold after the warranty expires and the impact of customer satisfaction derived from delivery of service on repeat buy behavior. Many firms find it advantageous to reduce the initial product sale price in order to capture the long-term revenue stream associated with delivering service (i.e., the famous "razor blade" strategy where the product is distributed free of charge in order to capture the revenue stream of support products from a captive user marker). Others focus on the design of their products and infrastructure in order to promote serviceability and to reduce the likelihood that customers will seek other sources of service in the after-market. ${ }^{1}$ In all cases, it is clear that the revenue a service provider can expect is a function of the specific service products designed and delivered to its customers.

\footnotetext{
${ }^{1}$ See Cohen and Whang [1997] for an economic analysis of the strategic tradeoff between product price and service quality. Cohen et al [2000] describes the celebrated case of Saturn and the automobile after-market. The Saturn case illustrates how high quality service drives revenue through retention of market share of after-market demand for post-warranty services as well as vehicle repeat buy behavior.
}

Draft - Do not distribute without permission Copyright 2004 
Service costs are driven by the wide range of long and short-term decisions that service supply chain managers make concerning deployment and control of resources. Operationally, these decisions typically are made in a manner that meets specific service targets while satisfying a variety of budget and resource constraints. ${ }^{2}$ Cost components include the direct costs of matching demand for service resources. These include the cost of parts consumption, fault diagnosis, material handling, transportation, and repair. There are also a variety of capital and fixed costs associated with the service business process. The most visible of these are the investment tied up in parts inventory and the fixed cost of warehousing and repair facilities. There are also considerable infrastructure, training and human resource fixed costs, which are associated with the service support function.

As we have noted, service performance is directly related to product availability or "up-time" and is the best surrogate for shortage costs. From a customer perspective, any measure of service should be directly related to the time delay between recognition of need for support service (e.g., an unscheduled maintenance due to product failure in the field) to the time of restoration of their product to its full operating condition in the field. From a service supply chain provider perspective, there are a variety of measures associated with availability of resources required to meet such customer needs. The principal internal metric is part fill rate, i.e., the fraction of demand for parts that is fulfilled by the stock available at the site receiving the demand. The primary measure used to capture the customer's perception of service quality is related to product availability, which is directly related to the delay times associated with matching supply with demand throughout the service supply chain. Both classes of service metrics (fill rate based and availability based) are functions of the underlying risk structure of future demand and the positioning and management of resources throughout the service supply chain. As we shall see, the specifics of how one computes such metrics and uses them will have a major impact on the design and implementation of effective decision support systems.

The tradeoff between these metrics can be best expressed using the concept of an efficient frontier curve. Recall that a wide range of resources are required to fulfill service demands in a manner consistent with the range of performance entitlements associated with the purchased service product(s). However, since the underlying demand processes are fundamentally random, it is critical to note that the timing, location, extent and consequences of a service demand cannot be forecast with certainty. Since the response times specified by the service product contracts typically are much shorter than the lead times for moving or acquiring material, and the timing of the demands is uncertain, it is necessary to position many of these assets prior to the fulfillment of the service demand, i.e., prior to the occurrence of the "service event". ${ }^{3}$ In general, the greater the promised level of service performance, the larger the required investment in such assets, which increases the total costs incurred by the service provider. For example, if no (or very little) inventory of parts is deployed, the financial cost of these assets is small. However, the response time to address each service event will be long since the required parts will have to be ordered from a backup location, or repaired. While the exact calculation of the relationship between service performance and costs is non-trivial, it can, nonetheless be performed using advanced analytical methodologies. The nature of this relationship can be depicted using the efficient frontier curve as shown in Figure 1. Note that the curve rises steeply: the costs increases disproportionately as the promised service performance level increases. Consequently, the revenue model must incorporate this relationship.

\footnotetext{
2 Service targets are required since the computation of actual shortage, downtime and delay costs to the service provider is not feasible. See (Cohen and Pierskalla [1979] and Cohen et al [2003] for empirical studies drawn from the blood distribution and semiconductor equipment industries, respectively, that demonstrate that managers typically under-estimate such costs.

${ }^{3}$ In a recent meeting, a major semiconductor fab operator charged its equipment suppliers to make parts required to repair a down machine on a fab line available within 15 minutes. The justification for this requirement was that having a line down costs the fab operator about $\$ 1$ million per day.

Draft - Do not distribute without permission Copyright 2004
} 
The primary service delivery challenge can now be more precisely stated as determining a way to deliver service products that meet pre-determined commitments for performance (in terms of cost and speed) in the most effective manner as defined by the cost/service efficient frontier. To be inside the frontier suggests inefficiency. To be on the frontier suggests that increasing the level of service for a service product can only be achieved at a higher cost. Balancing the tradeoffs among revenue, cost and service is challenging because of escalating service expectations, complexity of the service supply chain, and, as mentioned before, the high degree of uncertainty associated with service events. The DAD approach we are proposing, in fact, helps companies not only to negotiate their way on to the efficient frontier, but also pushes the efficient frontier downwards, as shown in Figure 1. This is precisely what allows firms to achieve quantum improvements in their service delivery performance and profitability.

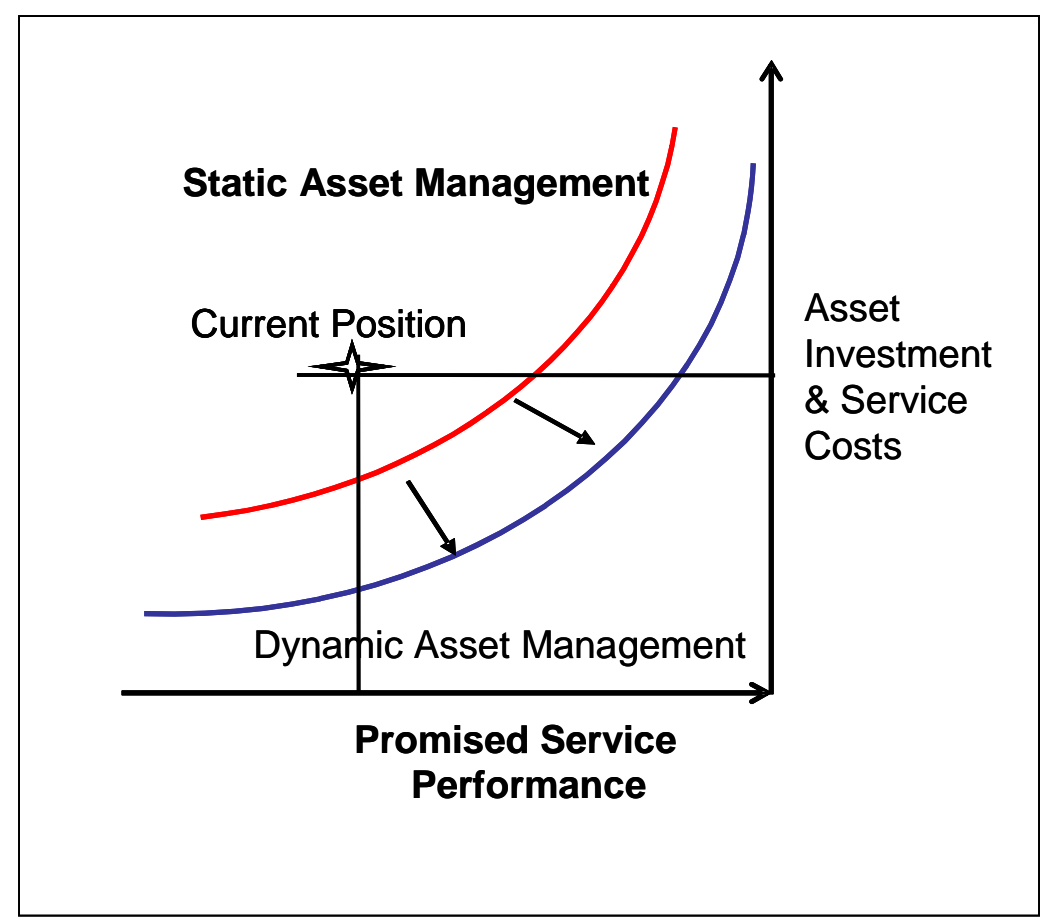

Figure 1. Key Tradeoffs for the Service Provider

\section{Service Asset Deployment Options}

In order to better understand how the revenue/cost/performance tradeoff noted above manifests itself in the service supply chain, we introduce a framework that considers a two dimensional hierarchy, based on the supply chain geography (geographical hierarchy) and the underlying product design architecture (product hierarchy). This joint geography/product hierarchy can be used to describe how the necessary resources are deployed and managed. In particular, for the particular case of after-sales service we will answer the question "where" (to deploy) in terms of the geographical hierarchy and "what" (to deploy) in terms of the product hierarchy. 
The product hierarchy can be described by breaking down the product into major modules, sub-modules and parts (see Figure 2). In the network representation shown, each node represents a particular item (finished product, module, sub-module, etc.) and the item membership specifics are captured by the arcs connecting an item to its parent(s) (the "goes into" items) and to its children (the "includes" items). The information required to specify a product hierarchy typically is encoded in the Bill of Material (BOM), which describes the recipe for producing the product. The "Service BOM" represents the current hierarchical structure used to maintain the product as it is configured in the field and therefore incorporates engineering changes and part supersession. Note that the Service $\mathrm{BOM}$ is not necessarily the same as the production BOM which is used for manufacturing functions.

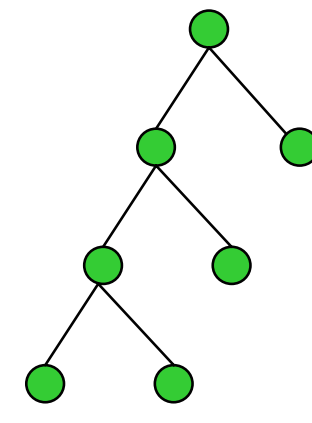

- End Product (Computer, Weapon System/Aircraft)

- Major Module (Field Replaceable Unit - FRU)

- Sub-Module (Shop Replaceable Unit - SRU)

- Piece Part (Consumable)

Figure 2. Product Hierarchy

A geographical hierarchy organizes stocking locations (nodes) by echelon to capture material and information flows associated with demand fulfillment in the service supply chain. At the lowest echelon, we position the individual forward locations, which could also include customer sites. At the "top" of the hierarchy we include the central stocking sites that act as emergency backup and/or replenishment sites for the downstream child locations. In between, the network might include additional field or regional stocking locations. Both emergency (customer) demand and replenishment demand flow "up" through the spatial hierarchy. The availability of material to meet these demands is determined by the inventory stocking policy for each part/location combination. This deployment of resources, along with the rules and procedures for matching supply with demand, drives the performance metrics related to lead times and customer service. Reverse material flows also occur in the spatial hierarchy to support repair of failed items. Figure 3 illustrates the basic elements of the material flow pattern found in a typical service supply chain.

Draft - Do not distribute without permission Copyright 2004 


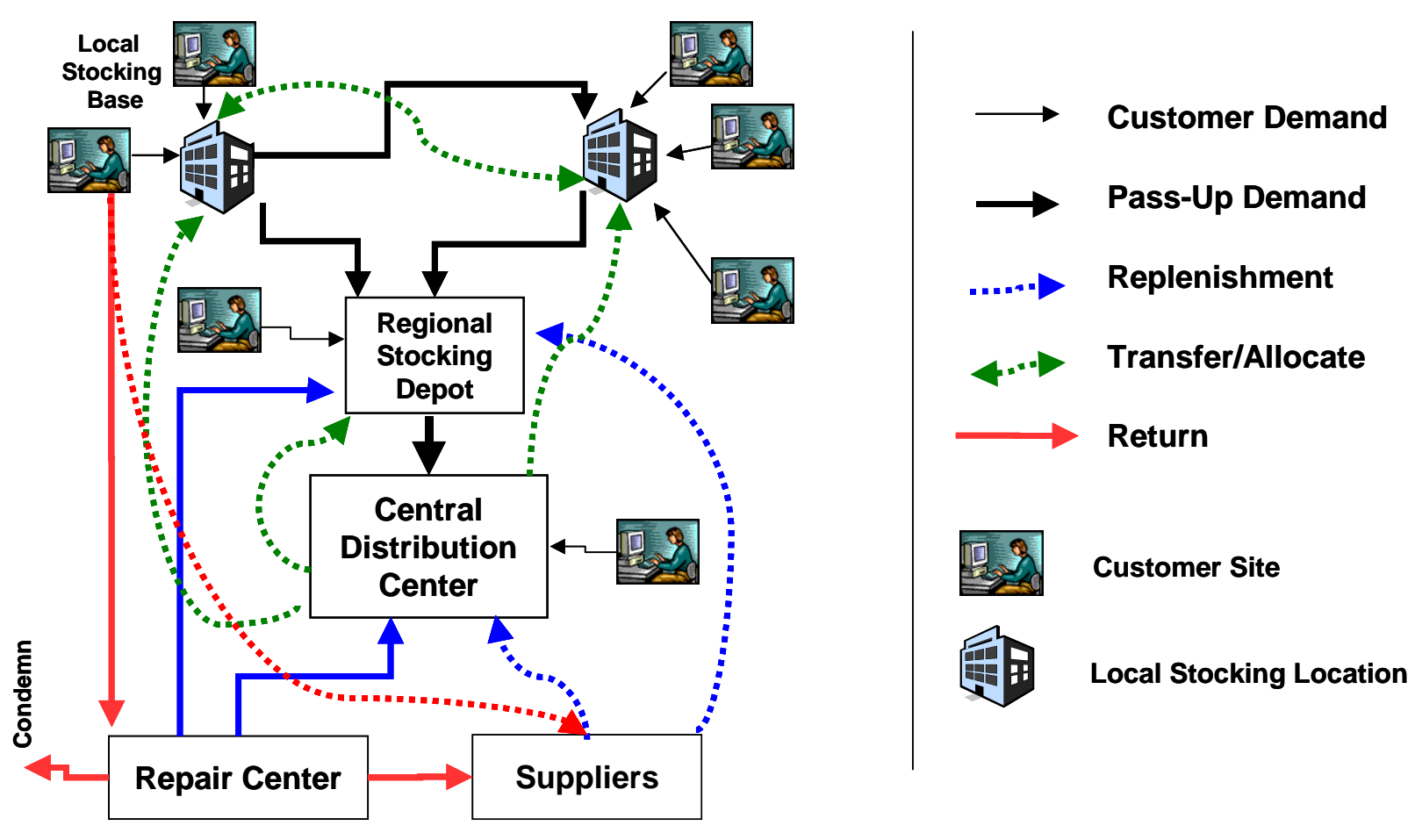

Figure 3. Multi-Echelon Service Supply Chain Material Flows

The interplay between these two hierarchies essentially describes a firm's service supply chain asset management strategy. Consider Figure 4, which illustrates how these hierarchies can interact. The fastest way to meet customer response time targets is to replace failed products with spare (standby) capacity units that are positioned at the customers' forward field locations. This is, of course the most expensive way to meet the need to restore a customer. However, depending upon the criticality of these products to the customer's mission, this may in fact be the appropriate strategy. For example, the routers produced by Cisco Systems for use in computer servers that support key financial transactions at a major financial institution incur high cost for the customer in case of failure. Consequently, a standby spare may be located very close to the customer's location (perhaps at the customer's location) so that downtime is minimal. Of course, the customer may be charged a premium for such service. On the other hand, the most economical way to meet the service demand is to identify and replace the specific components of the product that have failed and to do so at a central location. This can require time for extensive diagnosis and material movement. Repair in this case involves replacement or refurbishment of the failed components. This approach will of course be the slowest. A defect in specific components on a router circuit board for example could cause the router to fail. Replacement of these components, however, will be much cheaper then replacing an entire board assembly or the router itself. 


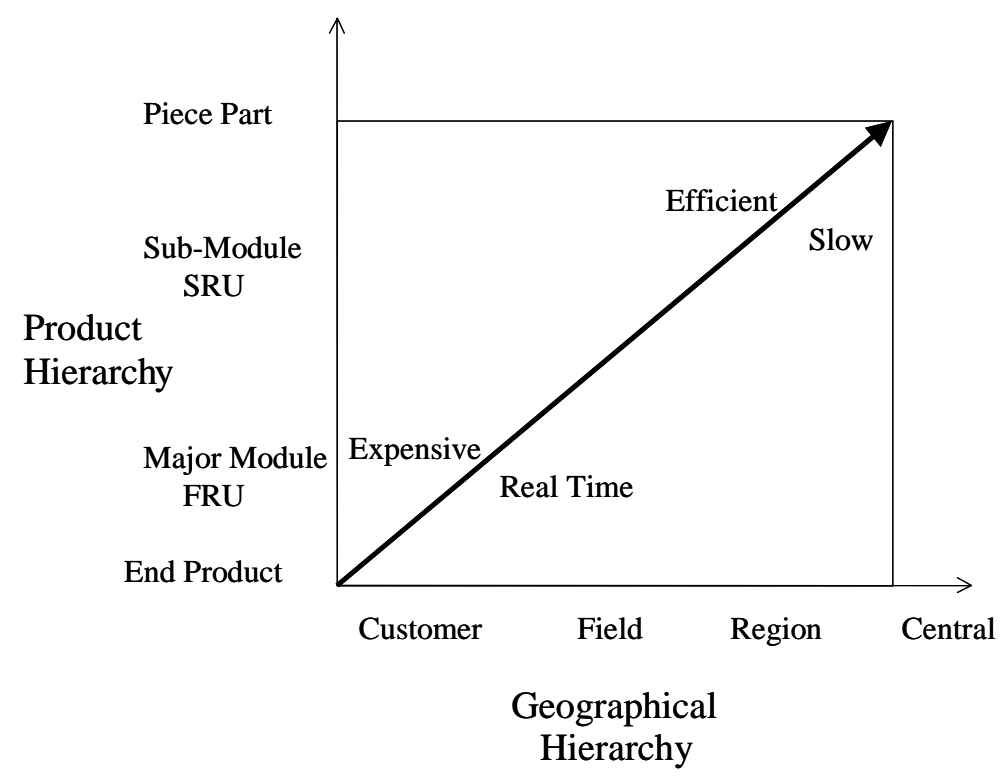

Figure 4. Tradeoffs Across the Geographical and Product Hierarchies

\section{Service Asset Decisions}

The joint geography/product hierarchies of Figure 4 provide a framework for understanding choices that a firm can make for positioning and managing the resources required to fulfill service demand entitlements. The geography hierarchy is concerned with the question of "where" such resources should be deployed. The product hierarchy focuses on the question of "what" should be deployed. These decisions must be made for all resource/location combinations. In typical environments, such as Cisco's, there are millions of such decisions to be made. It is important to note that these deployment decisions are highly inter-related in the sense that an investment in a resource at one location can and will influence investment decisions for many other item/location combinations that are connected via the joint hierarchy structure. For example, positioning resources of Field Replaceable Units (FRU's) at forward locations can decrease the emergency demands for piece parts that are experienced at higher echelon locations. Similarly, investing in additional safety stock at a central depot reduces the effective lead-time for replenishment at the "child" locations connected to it. This lead-time reduction will, in turn, affect the stocking requirements at the child locations. Alternatively, such decisions are often constrained by the budgets allocated to the service organization. Consequently, if a particular asset is assigned to a specific location, it affects what can be assigned to other locations. Thus, the service levels that can be offered to customers at various locations are affected by these decisions, and are, therefore, interrelated; a high level of service to one customer may imply a lower level of service to another.

In addition to the periodic deployment of assets, service providers must also manage the flow of such assets over time to replenish stock levels and to adjust deployments in anticipation of future service event requirements. This includes decisions concerning replenishment (purchase and repair) of assets consumed and re-deployment of assets within the service supply chain (allocation of incoming assets, transshipment of excess assets, etc.). Optimization of the full set of asset management decisions noted here also must include consideration of factors such as budget, cash flow and service constraints. Finally, we have observed that management of service operations requires planning with respect to a variety of performance objectives, including maximization of product uptime, minimization of total system costs and minimization of cash flow requirements associated with repair and purchasing. 
This service asset management problem is complicated further by the fact that many of the drivers of resource requirements (e.g., product utilization rates and deployments, evolving part failure rates, etc.) are non-stationary, i.e., they change over time. Thus the third dimension of resource deployment is concerned with the answer to the "when" question. Finally, as we have already noted, demand for the enabling assets are triggered by service events that are highly uncertain. As a consequence, solving the overall asset management problem requires a probabilistic, dynamic representation of its environment.

Given the complexity of the asset management problem, it is appropriate to decompose it into a collection of interrelated decision problems. Figure 5 illustrates a chronological, interactive planning hierarchy that mirrors the decomposition of managerial decision making that we have observed in many service supply chain environments. Each component corresponds to a different length of time, over which managerial tradeoffs and objectives must be considered as the relevant decisions are made (i.e., planning horizon). At the longest planning horizon we have Budget Planning, where decisions that determine specification of the overall service strategy are made. Such decisions can include design of the products being supported, the design of the "service products" that are offered to customers in the after sales market, and the design of the infrastructure used to deliver these service products. The planning horizon for budget planning is typically measured in months or years. As we proceed to the next level of decision making, Strategy Planning, the length of the planning horizon decreases. At this level, management is concerned with the strategic positioning of its material, human and knowledge resources, in anticipation of the need to meet customer service demands in a manner consistent with the response and cost entitlements as set out in the warranty and service agreements in force. These strategic resource deployment decisions give rise to a challenging optimization problem that must be solved periodically (daily, weekly), if the DAD strategy is to be implemented in a cost effective manner. At a nearer-in planning horizon (days or hours), we group the re-deployment decisions that are associated with re-positioning resources, usually within relevant lead times into the Tactics module. At this level we consider material flow decisions such as replenishment, allocation and transshipment.

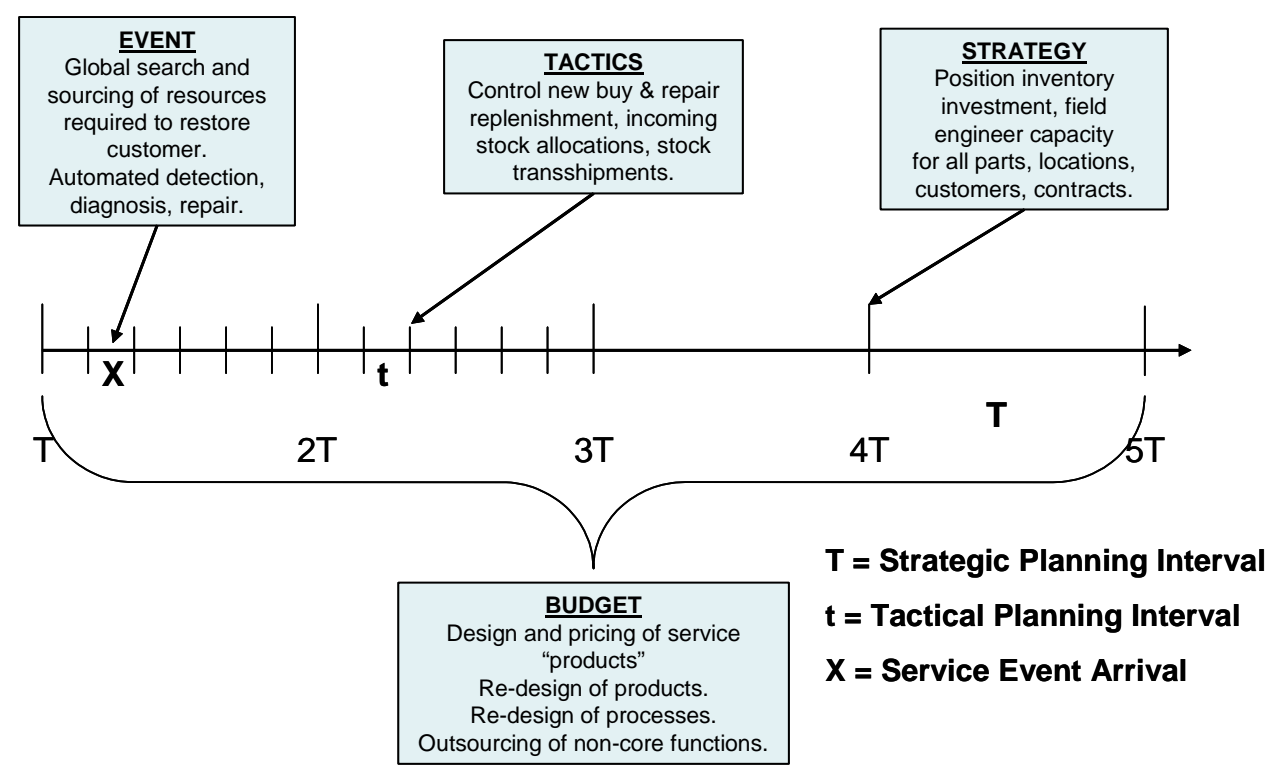

Figure 5. Interactive Decision Hierarchy 
It is important to note that all of the resource decisions described in Budget Planning, Strategy Planning and Tactics must be made prior to the occurrence of a particular service event whose fulfillment will require use of those resources. This is analogous to the purchase of a real option; a decision made prior to the exercise of that option. Contingencies that determine how and where the option to deliver service is exercised include occurrence of events, such as a product failure, or a maintenance event that cannot be predicted with certainty. Hence the decisions included in Budget Planning, Strategy Planning and Tactics are made on the basis of estimates of future resource requirements along with visibility of all of the events that affect supply and demand of such resources that have occurred throughout the service supply chain prior to the occurrence of the service event in question. In the DAD approach, we maintain that demand uncertainty cannot be eliminated through forecasting, and hence, trade-offs must be evaluated on the basis of future risk assessments captured by estimates of the demand probability distribution relevant to specific customer products and locations at particular future points in time. The decisions made at all pre-event planning levels, (Budget, Strategy and Tactics), thus constitute an exercise in risk management. 


\section{SERVICE DEMAND FULFILLMENT}

The "last mile" of decision making in the planning horizon hierarchy concerns fulfilling the service demands. We can view this as a problem of event management which is distinguished from all other planning/management problems discussed so far by the fact that it is concerned with decisions that are made after service event based demands for resources have been realized. At this level, managers control the real-time reaction of the service supply chain to shortages and excesses. Such responses ultimately determine how the service support process meets the strategic goals of customers. This is where the service product is actually "produced." Intelligent decision making here can improve the performance of the system by allowing managers to make the best use of current and projected resource deployments throughout the service supply chain. These choices will, in turn, act to mitigate the risks of service fulfillment delay through a mismatch in resource supply and demand.

\section{Actions to Fulfill Service Product Demands}

When the supply of the enabling assets is sufficient to meet the demands generated by service events, the system can fulfill demands from available resources. When demand exceeds supply at a location, however, managers of the fulfillment process have a wide range of actions that are available to them as they react, in real time, to the occurrence of a resource shortage. The following is a summary of some of the principle actions that an asset manager can consider in this situation:

- Demand transfer within the geographical hierarchy (lost sales) through vertical and lateral pooling - When material is not available at a stocking location the demand is transferred to an alternative location that acts as a backup site.

- Demand delay (backorder) - When demand exceeds supply the customer can be made to wait until the stocking location receives a shipment from a supply source (either as a new buy replenishment, internal transshipment of excess or receipt of a repaired item from a depot).

- Demand substitution down the product hierarchy - The repair or restoration of a customer's failed end product can be achieved in multiple ways. As noted the fastest way is to use Field Replaceable Units (FRU's) at the most forward location. In the event that required resources and/or repair capacity is unavailable, the requirement for repair can then be based on diagnosis and repair of an item at a lower level in the multi-indentured bill of material product hierarchy. Often, this transference of demand to a different item in the product hierarchy is associated with a shift to a more central and distant location that has the required capabilities and material.

- Horizontal demand substitution by an equivalent or superior item (this is different from substitution within the multi-indenture product hierarchy) - If an alternative part that can meet the requirements of the demanded part is available, then the alternative can be issued instead of the item that was originally requested. Typically the substituted item is more expensive and of superior performance quality (e.g., use of a $25 \mathrm{MB}$ disk drive to replace a $10 \mathrm{MB}$ disk drive).

- Resource rationing when customers with different service priorities call on common resources - One example is to not issue stock to meet a demand from a lower priority customer when the material is available (on-hand). The material is held back in anticipation of a demand that could emanate from a higher priority customer class. This is equivalent to allocation of backorders across different customer classes.

- Dynamic pricing and incentives to modify demands, which have caused the shortage - Use real time incentives and penalties to match supply and demand, e.g., provide a side payment to customers willing to wait for service fulfillment. This is analogous to overbooking management for an airline flight. 
It is instructive to consider some of the potential advantages and disadvantages associated with each of these fulfillment actions. Table 1 summarizes them.

Table 1. Service Demand Fulfillment Actions

\begin{tabular}{|l|l|l|}
\hline Fulfillment Action & \multicolumn{1}{|c|}{ Advantages } & \multicolumn{1}{c|}{ Disadvantages } \\
\hline Demand Transfer & $\begin{array}{l}\text { Decrease delay in responding to } \\
\text { unmet demand at forward locations } \\
\text { (when compared to backorder). } \\
\text { Efficient use of resources through } \\
\text { risk pooling. }\end{array}$ & $\begin{array}{l}\text { Demand met from alternative location } \\
\text { will take longer than an off-the-shelf } \\
\text { fulfillment. } \\
\text { Operational processes to support } \\
\text { demand pass-up and resource } \\
\text { pooling required. }\end{array}$ \\
\hline Demand Delay & $\begin{array}{l}\text { Simplifies control and analysis. } \\
\text { Directly related to customer-centric } \\
\text { service performance metrics, i.e., up- } \\
\text { time, availability. }\end{array}$ & $\begin{array}{l}\text { Increases response time for } \\
\text { customer. } \\
\text { Ignores pooling mechanisms that are } \\
\text { invoked by operational system. }\end{array}$ \\
\hline Demand Substitution & $\begin{array}{l}\text { Decrease delay in responding to } \\
\text { demand. } \\
\text { Avoid shortages. }\end{array}$ & $\begin{array}{l}\text { Usually a more expensive item is } \\
\text { substituted to fill the demand of a } \\
\text { less expensive item. }\end{array}$ \\
\hline Resource Rationing & $\begin{array}{l}\text { Maximizes positive effect of risk } \\
\text { pooling. } \\
\text { Avoids "free rider" problem whereby } \\
\text { lower priority customers may receive } \\
\text { same level of support as that } \\
\text { purchased by higher paying } \\
\text { customers. }\end{array}$ & $\begin{array}{l}\text { Operationally, difficult to implement } \\
\text { and explain. }\end{array}$ \\
\hline Pricing and Incentives & $\begin{array}{l}\text { Aligns incentives to promote "first } \\
\text { best" decisions that act to optimize } \\
\text { total supply chain performance. }\end{array}$ & $\begin{array}{l}\text { Contractual terms may be difficult to } \\
\text { verify and enforce. } \\
\text { Can disrupt market equilibrium } \\
\text { solution. }\end{array}$ \\
\hline
\end{tabular}

The heart of the DAD philosophy is not simply figuring out a way to implement such actions - for these actions have been observed at many companies - but to develop asset and resource management strategies that are based on the assumption that such contingent actions will be taken. In other words, it is not enough for the service supply chain to be able to react to mismatches between supply and demand; one must plan to be responsive and manage assets accordingly. This is precisely what sets our DAD philosophy apart from the collection of practices commonly observed at many companies, which we refer to as Static Asset Deployment (SAD) strategies.

For example, consider the case where two customers, who are served from the same forward location, have purchased service contracts that require the use of the same spare part. To avoid potential conflict in case of part shortages, the service provider may simply maintain two separate stockpiles of the same part, one for each customer. The inventory policy for each stockpile may be commensurate with the service level agreed to in the contract. While this approach is very easy to implement, and avoids potential conflict, it can be shown that it is much more cost effective for the service provider to realize risk pooling gains by combining the two stockpiles and serving both customers out of the same pool of inventory, (see Cohen, Deshpande and Donahue [2003] and Deshpande, Donahue and Cohen [2003] for an analysis of this problem in the context of military spare parts procurement at the U.S. Defense Logistics Agency). The problem, of course, is that the customer who has purchased the "cheaper" service contract gets to free-ride off of the higher service level contract. This is precisely where appropriately designed rules to ration inventory can avoid such problems while simultaneously accessing the benefits due to risk pooling.

15

Draft - Do not distribute without permission Copyright 2004 
The optimization methodology we describe later on explicitly plans for this possibility while determining optimal asset deployment strategies.

Similarly, consider the case where the service delivery system allows for the substitution of a more expensive, or higher quality, part for a cheaper one as a way to meet supply demand mismatches. Again, while companies following SAD strategies may be practicing such demand substitution in an ad hoc manner, it can be shown that asset deployment decisions resulting under the DAD methodology, which anticipates the possibility of demand substitution, are significantly more cost effective. In fact, this idea has been practiced for a long time in the context of yield management in the hospitality, airline and rental $\mathrm{car}^{4}$ industries. The DAD strategy attempts to implement similar approaches in the context of service delivery.

Thus, the fundamental characteristic of the SAD strategy is a lack of consistency or linkage to pre-event asset management decision-making. As a consequence when service events do occur, the resources needed to meet service product entitlement targets are not at the right place at the right time. Many adjustments have to be made in order to support the customer's current needs for support. This in turn leads to high levels of emergency transport, expediting and shortage penalty costs.

On the other hand, recourse-based asset planning, which explicitly accounts for the uncertainty associated with service events and the value of contingency actions, is fundamental to the DAD strategy. Optimization of asset management in the context of a DAD process leads to more robust deployments and more cost-effective ways of delivering the service promised to customers. This is a key point of departure from the SAD strategy typically followed by most companies. In this sense, our approach greatly resembles the well-known real-options framework that we alluded to earlier.

Our observations from the field confirm that the dominant mode of thinking in the SAD environment is based on static, deterministic forecasts that are more appropriate in finished goods DRP or MRP environments. The DAD and SAD strategies differ in other important ways as well. For instance, an important factor that should influence asset management decision-making is the wide range in attributes of the items being managed, e.g., unit cost, expected demand rate and lead times. A common approach to dealing with this issue is to create item classification groups and to use group membership as the driver of rule-based asset deployment decisions. The approach that we recommend as a part of the DAD strategy involves the development of a solution to a constrained optimization problem whose formulation captures the tradeoffs, interactions and constraints that have been noted as being relevant to service support. In a subsequent section we will describe how a state-of-the-art software system (introduced by MCA Solutions, Inc., www.mcasolutions.com) generates optimal solutions to variants of the problem that are consistent with DAD.

Other traditional approaches to solving the asset management problem are based on myopic heuristics, such as looking at only one product, one customer or one location at a time. In some cases the problem is decomposed into separable segments such as a central depot problem or a field location level problem that are solved in an independent manner. In many instances the product's service bill of material is ignored. The multiple (geography and product) hierarchies introduced suggest that there is a high degree of interaction across locations and items and hence managing assets in a way that ignores such interdependencies results in lower service and higher costs. The DAD methodology we have developed avoids such problems by explicitly considering such interactions in a comprehensive manner.

\footnotetext{
${ }^{4}$ Recall the offer made to you for an inexpensive upgrade to a larger sized car, or a better hotel room upon checking in. Typically, upon refusal by the customer, the upgrade is offered gratis. This is done because the smaller car, or the lower rate room, was unavailable, and the company had strategically planned to offer the better option as a substitute.
} 
We can summarize the distinction between static, SAD and dynamic DAD management practices by referring to Figure 6. As companies move to more advanced and comprehensive policies for asset management decision making, they have the opportunity to enhance the performance of their service demand fulfillment processes by improving the quality of decision making at both the strategic and tactical levels. At the Strategy level (denoted on the x-axis in Figure 6) we identify static methods that include specification of target service levels based on simple part classification rules or single location/single item models. The dynamic methods for Strategy incorporate tradeoffs across either multiple locations or indenture levels, where the most advanced approaches consider simultaneous interactions across both geography and product hierarchies. Tactical asset decision making, (denoted on the y-axis in Figure 6), can be broken down into two categories. At the basic/static level firms make unplanned expediting decisions to shift resources in a reactive manner, based on MRP/DRP logic, (i.e. using point forecasts and stationary forecasts). At the optimal/dynamic level, tactical decisions are based on assessment of cost and risk tradeoffs that respond to changing conditions in the environment.

If these two levels of asset management are optimized and effectively integrated, the firm will position assets based on long term strategic planning goals in a manner that meets service performance objectives at minimum cost or inventory investment. Firms will then be able to generate maximum service from their service resource investments as long as their asset re-deployment decisions are made in a manner that is consistent with the risk based forecasts and decisions generated at the strategic level. The result is a position in the upper right (Dynamic) quadrant. We have found, however, that most firms are positioned in the bottom left quadrant because they do not use appropriate methods at both the strategic and tactical levels or adequately integrate these levels of decision making.

A firm positioned at the top left quadrant will try to rebalance inventory to get the maximum service value, but given the lack of strategic optimization, they will find that their asset investments are in the wrong items at the wrong locations. Very few companies find themselves in this position. Those that do attempt to manage tactical redeployment in a risk based manner with sub-optimal strategic planning asset positioning (typically based on the use of basic planning methods), will achieve limited service benefits and/or experience high costs. Firms located in the bottom right quadrant do not adequately integrate strategic and tactical service asset management decision making. Such firms may position the right items at the right place, but will fail to reposition those assets in the short run based on recognition of short-term demand changes and anticipated supply shortages.

There is a natural progression from the lower left to the upper right quadrants as firms move from SAD asset management processes to DAD processes. As we shall see, doing so will improve service, lower investment requirements and lower operating costs.

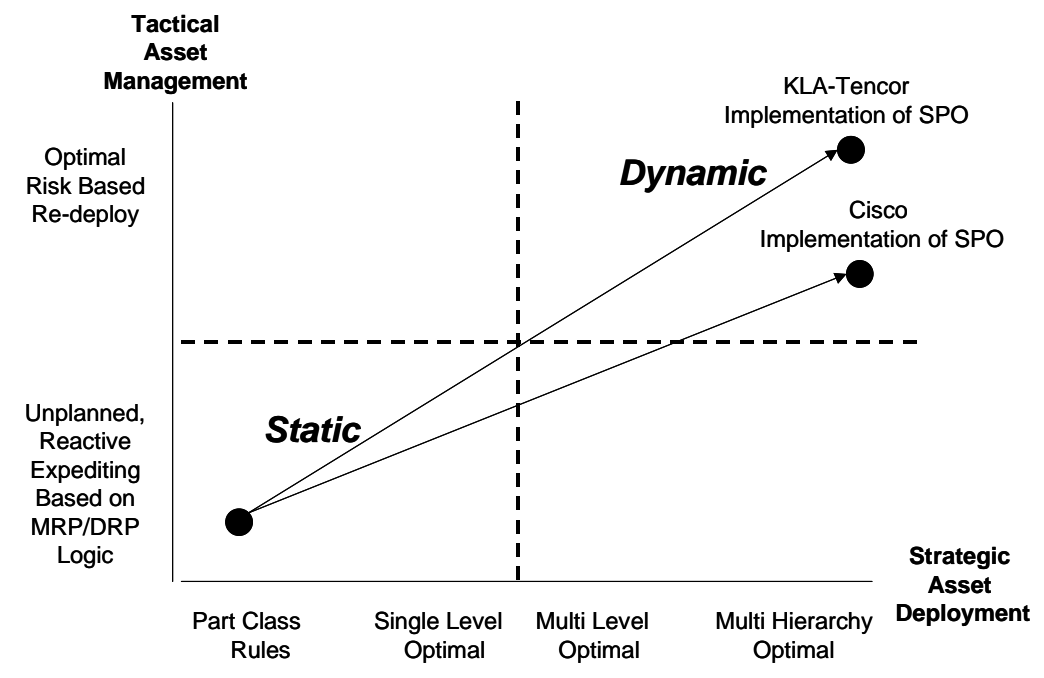

Figure 6. Service Asset Management

Draft - Do not distribute without permission Copyright 2004 


\section{PRACTICAL IMPLICATIONS OF DYNAMIC ASSET DEPLOYMENT:}

While conceptualization of a customer-centric service strategy is a necessary step, it is not sufficient for actualization of breakthrough service delivery performance. It is our observation that many service asset managers understand the need for flexibility and are constantly struggling to accommodate the high levels of risk and the complexities of their environment. The dynamic model for delivering customer service introduced here, we believe, is in fact, a true reflection of how such service process managers conceptualize their efforts to satisfy customer service needs. What has been lacking, however, are (1) effective decision support tools, (2) appropriate information technology to enable them to deliver the higher levels of service and efficiency that are required to support their company's service-centric service strategy goals and (3) a comprehensive approach to service product design.

In this section, we consider what it takes for firms to transform service supply chain strategies into actionable plans. We will, in particular, consider the question of how firms can effectively deliver differentiated service products to support their service-centric strategy goals in a dynamic, optimized, option based manner. In order to illustrate how this can be done we introduce a new generation of models, algorithms and software architecture that delivers service products in a dynamic and optimal fashion. A new company, MCA Solutions, Inc., has met this challenge with a web enabled, commercial software platform that has been successfully implemented in key high technology and aerospace industries where service support is mission critical. Their product, the Service Planning and Optimization (SPO) suite, synthesizes forecasting tools, optimization algorithms (at both the Strategy and Tactics level), and software developments that have been underway in the military and commercial environments for quite some time.

SPO’s risk management approach is based on the following three steps:

a) Probabilistic Forecasting

b) Optimized Resource Deployment (Strategy)

c) Optimized Resource Re-Deployment and Material Management (Tactics)

We note that implementation of SPO enabled Cisco to migrate from the lower left SAD quadrant, to the upper right DAD quadrant in Figure 6 through adoption of SPO enabled optimal Strategy level deployment of their inventory assets. Doing so allowed them to achieve the benefits of optimizing across multiple product and geography hierarchies. KLA-Tencor has augmented its initial SPO Strategy implementation with a recent adoption of the SPO Tactics module. Use of both Strategy and Tactics has allowed KLA-Tencor to achieve the benefits of full integration of inventory assets management decisions with optimal strategic target stocking levels.

Before we describe the three elements of SPO, we note that it acts as a decision support software system that that is linked to the underlying, transaction software systems that firms use to manage their service delivery processes, i.e., Enterprise Resource Planning (ERP), Supply Chain Management (SCM), Customer Relationship Management (CRM) and Product Life Cycle Management (PLM). Figure 7 illustrates the information/decision flows between SPO and these real-time systems. 


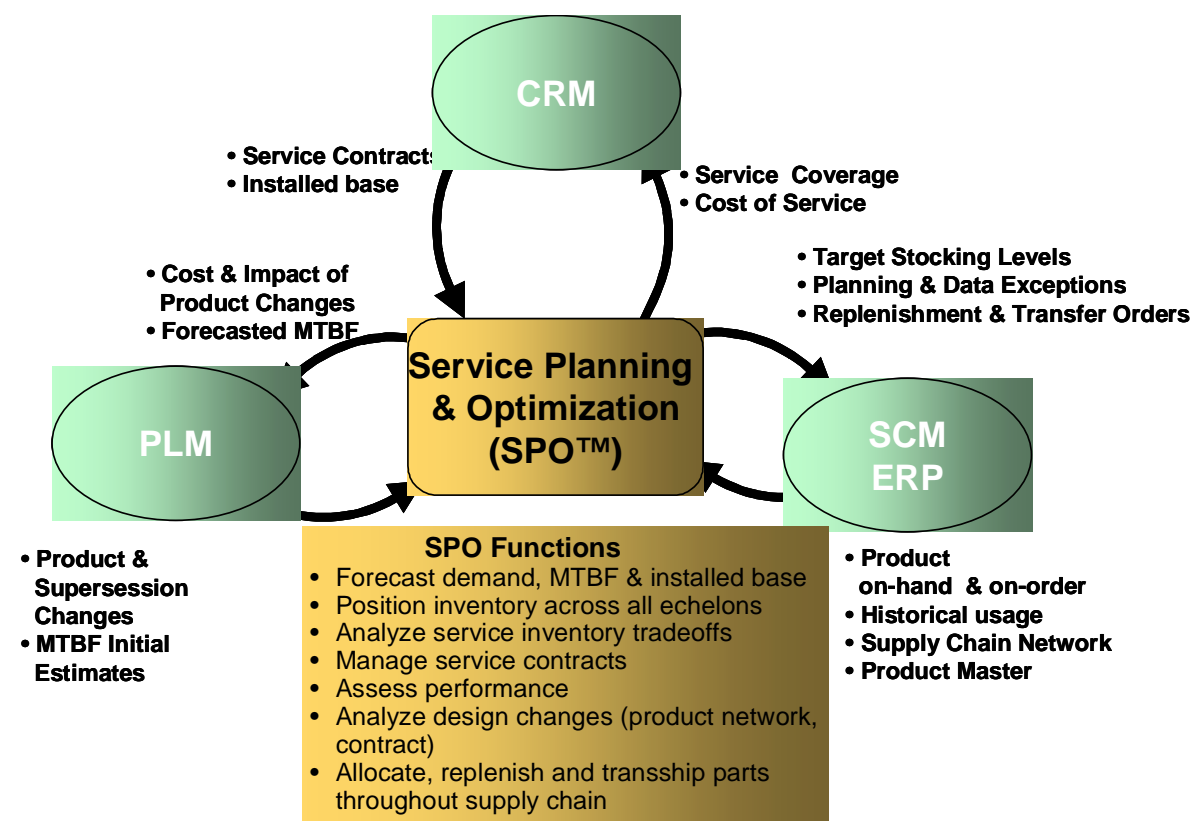

Figure 7. MCA Solution’s Service Planning and Optimization System Linkages

The integration and visibility capabilities of the system architecture, illustrated in Figure 7, enable the process flows for the SPO methodology that are illustrated in Figure 8.

\section{1) Forecast Probability} of Demand
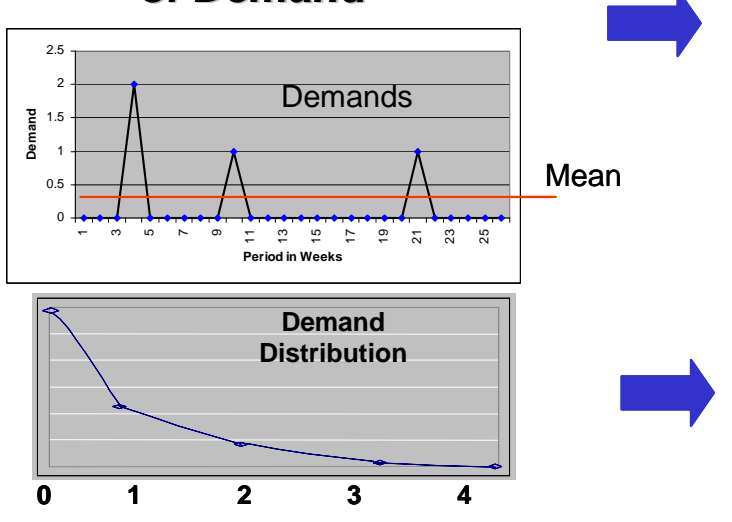

2) Determine Optimal Inventory

Positioning Strategy

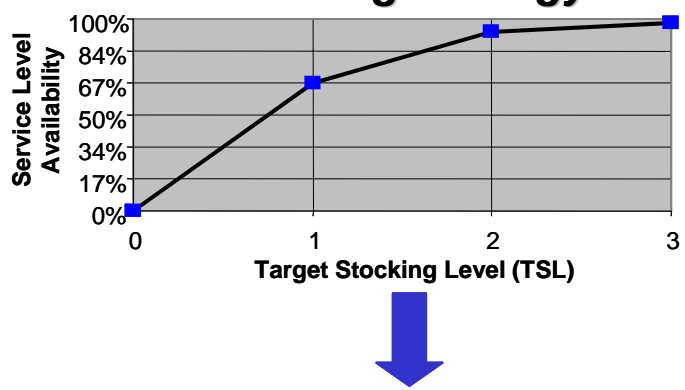

3) Re-Deploy / Execute to Optimal Plan

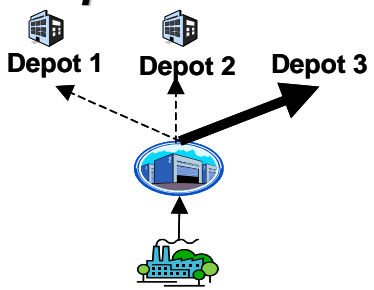

Figure 8. SPO’s 3 Step Risk Management Process 
We now consider each of these modules, in turn, and examine how they act to support a dynamic asset management approach.

\section{a) Forecasting:}

As we have noted, current approaches to service supply chain decision support are often based upon manufacturing (ERP), or finished product logistics (DRP), thought processes. In these environments, it is customary to generate forecasts of future demand and to use such forecasts as an input to resource deployment decisions to determine master production scheduling and finished product distribution. In the after-sales environment, which is characterized by many, very low demand items and dispersion of demand over multiple customer locations, the treatment of an estimate of future demand as a point value (deterministic number) can be quite misleading. While uncertainty is reduced as the planning horizon compresses (i.e., as we move from Budget to Strategy to Tactics decisions), it is not eliminated. Since, in many cases, demand is low (e.g., the expected usage of a part at a location is 0.1 units per month), additional assumptions must be made to convert fractional forecasts into discrete values and to schedule the arrival of these rounded quantities.

The principle requirement to support a real option model is to have accurate estimates of future risks. In SPO, parameters describing probability distributions of item/location demand are generated. These forecasts are influenced by both historical (time series) and causal factors. In effect SPO generates a "blended" forecast that takes a weighted average of time series and causal parameter estimates. Factors such as mean time between demand, local installed population, and projected end product utilization are used to come up with the causal component.

\section{b) Integrated, Risk Based Optimization Model for Asset Management}

Service asset management in SPO is concerned with calculation of optimal resource deployment plans, where optimization refers to maximization of service performance subject to budget, risk and multiple hierarchy interaction constraints. The underlying decision problem at the Strategy level has been formulated as a constrained optimization problem where the decisions include the location, quantity and capabilities of the resources deployed (e.g., target inventory stocking levels for every part/location). The objective of this optimization is to maximize service, as it relates to customer satisfaction (e.g., availability of the products) or to minimize relevant costs (inventory investment, cash flow, etc.). Constraints include the interactions in the product/geography hierarchies as well as limits on budgets, cash flows and support capacities.

Note that this is a very challenging discrete, non-linear, stochastic decision problem. Probabilistic forecasts are input to the Strategy formulation and the underlying model structure builds on the extensive modeling research in the area of multi-echelon, multi-indenture inventory modeling. The optimization algorithms embodied within SPO Strategy are based on extensions to methodologies that have been developed for this class of problems in military and high technology applications, (see Cohen et al[1990] and [1999] for selected applications at IBM and Teradyne respectively).

The decision problem at the Tactics level involves managing the flow of materials within lead times. The specific decisions include new buys, repairs, allocations and excess stock transshipments. Other (human resource) asset redeployments can also be considered at the Tactical level. The constrained optimization problem to be analyzed here trades off costs (including transportation, ordering and handling) against the service impact (again as measured by impact on the underlying risk of shortage and delay). Advanced filtering and triggering technology is used by SPO to limit the demands on service management for recommended action review. 
A novel feature of SPO's Tactics module is its capability to quantify the risk profile for each part/location based on accurate information concerning the item's inventory position (on-hand, in repair, defectives on route, confirmed new buy orders, etc.). The basic idea is to use the probability distribution forecasts for item demand as an input and to compare projected material flows against projected demand scenarios. Accurate current system status is retrieved from the underlying operational (transaction) systems. The SPO forecast module generates the forecasts (as noted above). Optimized target stocking levels are generated by the SPO Strategy optimization engine and input to SPO Tactics. SPO Tactics provides the asset manager/user with tools to identify those locations and items that are facing the greatest risk (of shortage or backorder delay). A typical output is illustrated in Figure 9.

Firm Orders

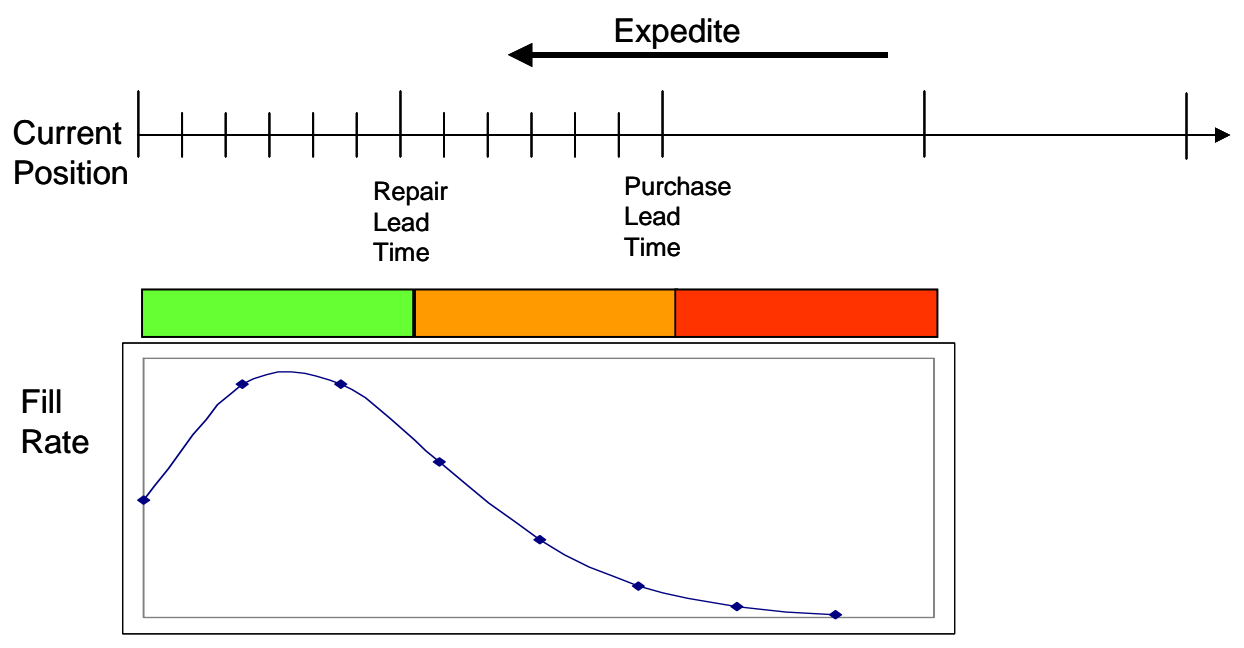

Figure 9. Shortage Probability Risk Assessment

It is important to note that in many service support environments it is typical for managers and their support systems to separate decision-making across the planning horizon hierarchy as well as across the product and geography hierarchies. Thus, in such cases, strategic resource deployment decisions are determined on the basis of one set of data and assumptions and tactical re-deployments are managed on the basis of different and potentially inconsistent data and assumptions. Interaction between decisions is therefore ignored and, as a result, potential performance improvement benefits are lost. Also, event management is often carried out by processes that are not coordinated with service asset management planning and with little or no visibility into current and projected resource positions. The result is uncoordinated decision making that leads to frequent adjustments at the tactical and event levels. SPO provides one mechanism for integrating these decisions.

The capabilities that SPO provides in support of dynamic asset management include the following:

- Resource deployments at the Budget and Strategy levels are made in a manner that accounts for process interactions throughout the product and geography hierarchies. Specifically, with SPO, managers can position resources (e.g., service parts) to maximize revenue or minimize cost subject to service performance and resource constraints.

- The optimization will explicitly consider the impact of risk and uncertainty by treating forecasts of future resource requirements as estimated probability distributions. 
- The forecasting and optimization system can be implemented in an environment with full access to comprehensive data derived from service related transactions that occur throughout the service value chain. Such transactions are controlled by execution software systems that are used to support customer relationship management, enterprise material flows, supplier linkages, and service personnel management.

- The resulting decision support system has the ability to optimize the full range of service supply decisions with algorithms that yield answers rapidly and which take into account the product/geography interactions noted above, as well as the differentiated service product performance targets and resource constraints. Such high performance algorithms are necessary to support effective decision making at all steps in the planning horizon hierarchy. Speed and optimality are especially important to enable a high level of coordination between customers, service providers, product manufacturers and part producers.

- The Budget and Strategy resource deployments generated in this fashion are integrated with the Tactics management function where resource re-deployment decisions are made. Again, visibility, optimization and explicit consideration of risk are included.

- There is a tight linkage back to execution systems where event management takes place.

\section{Service Product Design}

While our focus thus far has been on the mechanisms that enable service delivery, it is important to recognize that in order to be successful in competing through service-centric strategies, a firm must also design the appropriate service products. In order to do so the firm must consider the cost and performance tradeoffs associated with service product design and delivery from the perspective of both the customers and the suppliers of after-sales services. Service product design will be considered here in terms of positioning service products with respect to those attributes that are relevant to customers seeking after-sales service support.

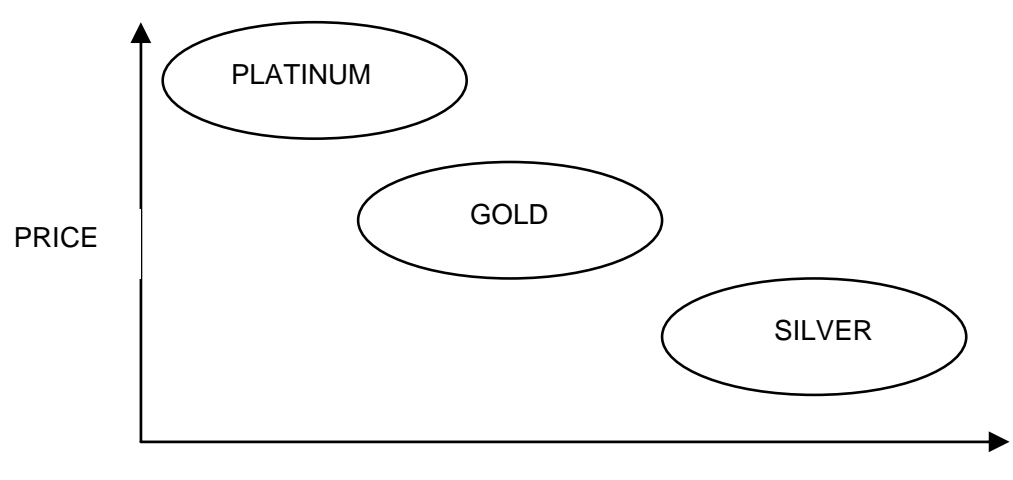

RESPONSE TIME

Figure 10. Customer Service Strategies

Draft - Do not distribute without permission

Copyright 2004 
The principal objective of a customer who purchases a product is to derive maximum benefit from its use over the full ownership cycle. The key tradeoff that drives customer satisfaction in the context of product ownership and use ultimately is between cost and response time; specifically between the price charged for the service (usually sold in the form of a post-warranty service contract or bundled into the product purchase price through the terms of the warranty), and the performance promised by that contract or warranty. Such performance is measured, from the customer's perspective, by the response time required to restore an installed product to its full operational capability in the event that it requires repair, maintenance, upgrade or support. As a result, we can define service products by their position in the time/cost space. Consider Figure 10 which illustrates how products can range from the fast but expensive (Platinum) to the slow and economical (Silver). A company like Cisco Systems offers two-hour service contracts (Platinum) as well as two-day service (Silver), of course, at different prices to their customers. Thus, consumers of essentially the same product may choose different services based on reasons that include criticality of their assets and their willingness-to-pay. Note that service products can be highly differentiated and perhaps even customized in terms of their price/performance position in order to match the diverse needs and willingness to pay of the various market segments that demand service support.

The price/response time tradeoff forms the basis of designing differentiated service products that are positioned to meet the needs of customer segments that are distinguished by the utility they give to cost and service performance. Service product design requires additional specification of contract terms that are tied to realized performance (e.g., performance based payments and/or penalties). Terms for such service product contracts can also lead to constraints on asset management decisions such as introducing a requirement for a minimum stocking level for all Platinum customers.

In addition to considering the impact of the service products offered on the performance and profitability of the service supply chain, a number of other broader issues are also relevant during the process of product design. First, the issues noted thus far in the paper clearly point to the importance of developing a detailed understanding of the specific service needs of individual customers. This implies that the traditional practice of classifying customers on the basis of only sales volume, geography, technological capabilities, etc. is not enough for our purposes. In fact, it may be misleading. What is particularly important is to determine a way to classify customers based on their specific service needs. For example, the service supply chain strategies for customers with Platinum service needs may be very different from those with Bronze services needs, regardless of the size of the customer. Alternatively, geographical proximity of a Platinum and Bronze customer may imply that it makes sense to pool their service asset requirements.

Second, it is extremely important that firms try to rationalize the size of the service product portfolio offered to customers. Our field experience has provided ample evidence of companies following SAD strategies that either adopt a one-size-fits-all approach to service, or offer an excessively large number of service products. Either strategy can prove to be detrimental to performance and profitability. The optimization methodology that we have described earlier can help identify the optimal mix of service products that can maximize the synergies that might exist between the resource requirements of the service products in ones portfolio. 


\section{CONCLUSION}

The concept of flexibility is not new! In fact, it has been a key mantra followed by many in the area of supply chain management for production materials. Indeed, managers of service supply chains have always recognized that they are engaged in a high stakes gamble requiring decision making in a complex and risky environment. The dynamic asset deployment approach that we are proposing here is a way to introduce the concepts of flexibility and planned responsiveness formally into the area of service delivery. Up until recently the analytical tools, data visibility and information systems integration required to implement such flexibility have not been available. The DAD strategy and software tools to support it, which are described in this paper, can help service supply chain managers to achieve the goal of supply chain flexibility. Companies cannot afford to neglect the potential of this approach in today's hyper-competitive, customer-centric world where service is often the key competitive differentiator.

A useful way to summarize the key elements of the DAD strategy is as shown in Figure 11. The cornerstones of effective and profitable service delivery are effective service product design, service asset management, and service demand fulfillment. It is crucial for companies to recognize the interactions between these three levels of decisionmaking. Companies that have embarked upon this path (from SAD to DAD) have met with resounding successes in a very short time, as evidenced from the results of the three case studies described earlier, where such strategies were implemented. At Cisco Systems, investments in service assets reduced by about $21 \%$, while service levels increased by $10-15 \%$. At KLA-Tencor, the results were even more dramatic - service assets reduced by about $28 \%$, and service levels improved by nearly $18 \%$. Similar improvements are anticipated at Boeing as well. We are, therefore, convinced that companies that are willing to invest in this comprehensive, scientific and analytically based approach to customer service are poised to be on the forefront of the competitive landscape in their respective industries.

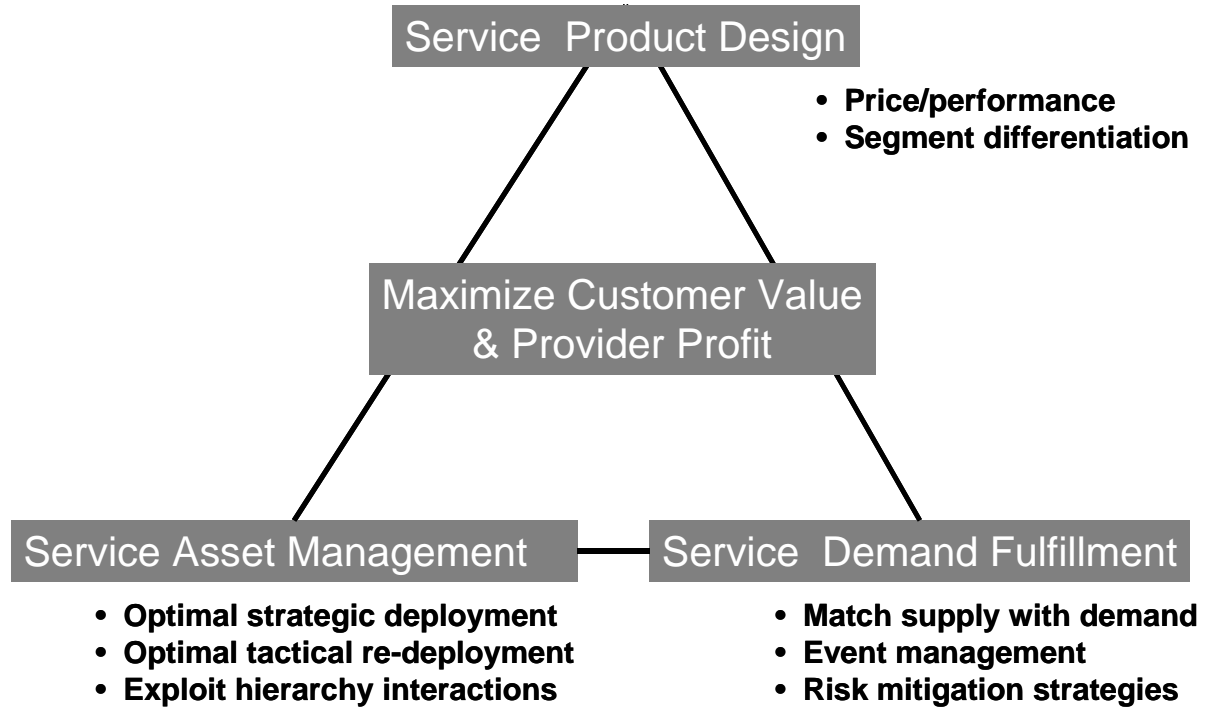

Figure 11. Service-Centric strategy is Enabled by Dynamic Asset Deployment 


\section{References}

1. J. Bijesse, M. McCluskey and L. Sodano, "Service Lifecycle Management (Part 1): The Approaches and Technologies to Build Sustainable Competitive Advantage for Service,” AMR Research Report, August, 2002.

2. M. J. Dennis and A. Kambil, “Service Management: Building Profits After the Sale,” Supply Chain Management Review, Jan.-Feb. 2003, 42-49.

3. R. Wise and P. Baumgartner, "Go Downstream: The New Profit Imperative in Manufacturing," Harvard Business Review, Sept.-Oct. 1999, 133-141.

4. E. Liang, "Optimizing the "Other Supply Chain": Software Breakthroughs in the Service Supply Chain Market,” White Paper, Battery Ventures, San Mateo, CA, http://www.battery.com/, Jan 2002.

5. M. A. Cohen and S. Whang "Competing in Product and Service: A Product Life-Cycle Model." Special Issue of Management Science on Frontier Research in Manufacturing and Logistics, Vol. 43, No. 4, April 1997, pp. 535-545.

6. M. A. Cohen, H. Lee, C. Cull and D. Willen, "Supply Chain Innovation: Delivering Values in After Sales Service,” Sloan Management Review, Vol. 41, No. 4, Summer 2000, pp. 93-101.

7. M. A. Cohen and W. Pierskalla, "Target Inventory Levels for a Hospital Blood Bank or a Decentralized Regional Blood Banking System.” Transfusion, Vol. 19, No. 4, July-August 1979, pp. 444-454.

8. M. A. Cohen, J. Ren, T. Ho and C. Terwiesch, "Measuring Imputed Cost in the Semiconductor Equipment Supply Chain,” Management Science, Volume 49, No.12, 2003

9. M. A. Cohen, V. Deshpande and K. Donohue, "An Empirical Study of Service Differentiation for Weapon System Service Parts.” Operations Research, Vol. 51, No. 4, 2003.

10. V. Deshpande, V., M.A. Cohen and K. Donohue, "A Threshold Inventory Rationing Policy for Service Differentiated Demand Classes,” Management Science, Vol. 49, No. 6, 2003.

11. M. A. Cohen, A.Tekerian, P. Kamesam, H. Lee and P. Kleindorfer, "OPTIMIZER: IBM's Multi-Echelon Inventory System for Managing Service Logistics.” Interfaces, Vol. 20, No. 1, January-February 1990, pp. 65-82.

12. M. A. Cohen, Y. Wang and Y-S. Zheng, "Identifying Opportunities for Improving Teradyne’s Service Parts Logistics System.” Interfaces, Vol. 29, No. 4, July-August 1999, pp.1-18. 